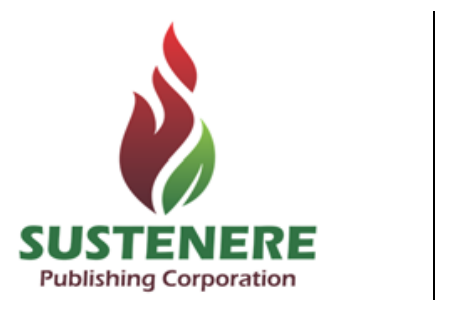

Revista Brasileira de

Administração Científica,

Aquidabã, v.5, n.3, Jul, Ago, Set,

Out, Nov, Dez 2014.

ISSN 2179-684X

\section{SISTEMAS DE GESTÃO DA SEGURANÇA E SAÚDE NO TRABALHO: ENTRE A NORMALIZAÇÃO E A REGULAMENTAÇÃO}

\section{RESUMO}

O objetivo principal do presente artigo é possibilitar um entendimento dos sistemas de gestão de segurança e saúde no trabalho - SGSST. O estudo é baseado em pesquisa na legislação, normas e bibliografia específica e aborda conceitos relativos a normalização, regulamentação, acreditação e avaliação da conformidade e cita os modelos de SGSST de alguns países e o brasileiro, apresentando a norma ABNT NBR 18801 em linhas gerais e a perspectiva brasileira de regulamentação dessa matéria. Por fim, são apresentadas considerações relacionadas à regulamentação ou adoção da norma técnica, tendo como base a teoria, um estudo específico relativo a SGSST e as boas práticas de regulamentação.

PALAVRAS-CHAVES: Sistema da Gestão de Saúde e Segurança no Trabalho; Normalização; Regulamentação; Boas Práticas de Regulamentação.

\section{HEALTH AND SAFETY MANAGEMENT SYSTEMS AT WORK: BETWEEN THE STANDARDIZATION AND REGULATIONS}

\section{ABSTRACT}

The main objective of this paper is to enable understanding of health and safety management systems at work - HSMS. The study is based on research in the legislation, standards and specific bibliography and discusses concepts related to standardization, regulatory, accreditation and conformity assessment and mention HSMS models of some countries and Brazilian model, with the ABNT NBR 18801 in general and the Brazilian perspective to regulation of this matter. Finally, are present considerations related to regulations or adoption technical standard, based on the theory, a specific study on the HSMS and best regulatory practice.

KEYWORDS: Health and Safety Management System at Work; Standardization; Regulation; Best Regulatory Practices. 


\section{INTRODUÇÃO}

O desenvolvimento do presente estudo teve origem no impasse relacionado aos temas normalização e regulamentação instaurada entre a atuação da autoridade regulamentadora referente à segurança e saúde no trabalho e do organismo nacional de normalização brasileiro. Por solicitação do Ministério do Trabalho e Emprego - MTE, alegando o fato de ter instituído grupo de trabalho para elaboração de uma Norma Regulamentadora referente ao tema sistema de gestão da segurança e saúde no trabalho, a Associação Brasileira de Normas Técnicas - ABNT prorrogou o prazo para o início da vigência da norma ABNT NBR 18801, que trata do mesmo tema, de dezembro de 2011 para dezembro de 2014. Com isso, pretende-se apresentar um entendimento geral distintivo entre normalização e regulamentação relacionada a sistemas de gestão da segurança e saúde no trabalho e, ao final, inserir algumas considerações relacionadas à regulamentação com a possibilidade de adoção da norma técnica, tendo como base a teoria, um estudo específico relativo a esse tema e as boas práticas de regulamentação internacionalmente recomendadas.

\section{METODOLOGIA}

Para discorrer sobre esse tema, a princípio serão apresentados alguns conceitos e aspectos relevantes a respeito de regulamentação e normalização e por consequência, relativos a normas, normas técnicas, regulamentos, regulamentos técnicos, acreditação e avaliação da conformidade. Em seguida, serão apresentados preceitos referentes à utilização de normas técnicas na regulamentação. Posteriormente, o artigo prosseguirá discorrendo sobre as competências legais dos entes responsáveis pela normalização e regulamentação no Brasil, apontando os entes envolvidos e as competências da Associação Brasileira de Normas Técnicas, do Comitê Brasileiro de Normalização, do Comitê Brasileiro de Regulamentação, do Comitê Brasileiro de Avaliação da Conformidade, do Instituto Nacional de Metrologia, Qualidade e Tecnologia e do Ministério do Trabalho e Emprego. O estudo, na sequência, discorrerá sobre os modelos de sistemas de gestão da segurança e saúde no trabalho em diversos países do mundo, quer seja por meio de normalização, cuja adesão é voluntária, ou de regulamentação que normalmente impõe a necessidade de cumprimento obrigatório pelas empresas. No mesmo capítulo será apresentado um panorama geral referente à normalização e à regulamentação do tema no Brasil e será apresentado ainda em linhas gerais o modelo de sistema de gestão da segurança e saúde no trabalho proposto na norma ABNT NBR 18801:2010. Por fim, serão feitas recomendações relacionadas à regulamentação com adoção da norma técnica, tendo como base a teoria, um estudo específico relativo ao tema e as boas práticas de regulamentação. 


\section{REVISÃO TEÓRICA}

\section{Normalização e Regulamentação}

Antes de se iniciar a discussão a respeito dos sistemas de gestão da segurança e saúde no trabalho, faz-se necessário apresentar algumas definições relacionadas às atividades de regulamentação e normalização, as quais são tidas como relevantes para melhor compreensão do presente artigo.

A primeira definição importante é o conceito de normalização. De acordo com a norma ABNT (2006, p.1), normalização é a "atividade que estabelece, em relação a problemas existentes ou potenciais, prescrições destinadas à utilização comum e repetitiva com vistas à obtenção do grau ótimo de ordem, em um dado contexto". O mesmo Guia aponta que, em particular, a atividade de normalização consiste nos processos de elaboração, difusão e implementação de normas.

Segundo Mitrulis (1990), a normalização compreende a formulação e a aplicação de regras para um tratamento ordenado de uma atividade específica, para o benefício e com a cooperação dos interessados e, em particular, para a promoção do desenvolvimento econômico de empresas, países e regiões, levando em consideração condições funcionais e requisitos de segurança. Essas regras são genericamente denominadas 'normas'.

Inserido no conceito de normalização, encontra-se o termo 'norma'. De acordo com a norma ABNT (2006, p.4), norma é um "documento estabelecido por consenso e aprovado por um organismo reconhecido, que fornece, para uso comum e repetitivo, regras, diretrizes ou características para atividades ou seus resultados, visando à obtenção de um grau ótimo de ordenação em um dado contexto". É conveniente que as normas sejam baseadas em resultados consolidados da ciência, tecnologia e da experiência acumulada, visando à otimização de benefícios para a comunidade. Dependendo do conteúdo de uma norma, ela pode ser classificada como 'norma técnica', a qual, segundo CONMETRO (2007, p.5) é definida como sendo:

Documento estabelecido por consenso e emitido por um organismo reconhecido, que fornece para uso comum e repetido, regras, diretrizes ou características para produtos, serviços, bens, pessoas, processos ou métodos de produção, cujo cumprimento não é obrigatório. Pode também tratar de terminologia, símbolos, requisitos de embalagem, marcação ou rotulagem aplicáveis a um produto.

Existem normas técnicas internacionais, as quais são assim definidas por serem estabelecidas por um organismo internacional de normalização para aplicação em âmbito mundial, com participação dos organismos de normalização de todos os países. Diversos organismos internacionais podem efetuar a normalização como a ISO - International Organization for Standardization e, em campos específicos, a IEC - International Electrotechnical Commission, área elétrica e eletrônica, o ITU - International Telecommunications Union, em matérias relativas a telecomunicações, e a Codex Alimentarius Commission, no campo da segurança alimentar. 


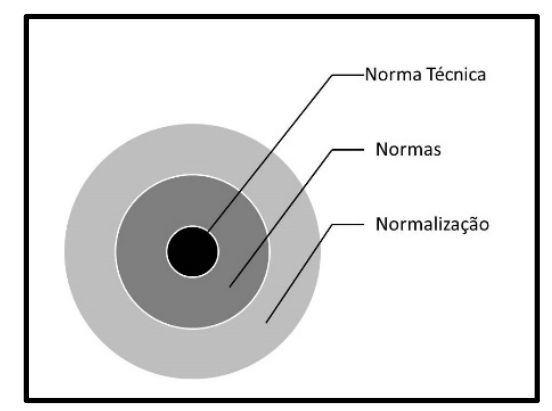

Figura 1: Relação entre os Conceitos de Normalização, Norma e Norma Técnica.

As normas internacionais são reconhecidas pela Organização Mundial do Comércio - OMC como a base para o comércio internacional e sua adoção em nível mundial possui como objetivo principal a superação de eventuais barreiras técnicas. Existem também organismos de normalização regionais, compostos por organismos de normalização dos países membros dos blocos regionais numa região geográfica, econômica ou política do mundo, a exemplo do Comitê Europeu de Normalização - CEN, da Comissão Pan Americana de Normas Técnicas - COPANT e da Associação Mercosul de Normalização - AMN.

A participação brasileira nos trabalhos de normalização da ISO é efetuada através da ABNT, que é uma entidade privada sem fins lucrativos com competência para normalização no âmbito nacional e participação nos fóruns internacional e regional de normalização reconhecida pelo Estado brasileiro. Por fim, concluindo as explicações relacionadas aos níveis de normalização, e salutar mencionai que dentro dos países também poderá ocorrer normalização territorial ou em partes de uma organização ou setores (por exemplo, um Ministério), nível local, e associações, indústrias, fábricas, oficinas e escritórios. (ABNT, 2005, p. 2).

Finalizando a apresentação dos aspectos conceituais relacionados a normalização não se pode deixar de destacar que um dos papéis estratégicos da normalização é o de conferir a base técnica, em níveis adequados, para o processo de regulamentação, situando-se, portanto, como ferramenta de suporte à ação do Estado.

Segundo Oliveira (2010, p.17), o termo regulamentação é conceituado com diferentes abordagens, conforme as perspectivas adotadas pelos especialistas sobre o tema. É possível encontrar diferentes conotações e significados para esse termo nas agendas políticas de diferentes governos. O presente estudo, não possui como objetivo propor uma definição que abarque toda essa diversidade, sendo apresentados somente os principais aspectos jurídicos e um enfoque no conceito internacionalmente aceito.

Oliveira (2007, p.25) apresenta a doutrina jurídica referente ao tema regulamentação, passando pelo sentido estrito (advindo do Direito Constitucional) que exige que a competência privativa de regulamentar seja exercida pelo chefe do poder executivo, conforme entendimento do jurista Celso Antônio Bandeira de Mello, e concepções que entendem regulamento, no sentido lato, como qualquer documento normativo (geral e abstrato) emanado dos órgãos da administração pública. Seguindo esse entendimento, dependendo da abordagem, no âmbito da 
administração pública qualquer documento normativo poderia ser definido como regulamento. Nesse sentido, Oliveira (2007, p.25) apresenta o entendimento de que qualquer instituição do executivo poder exercer a função regulamentar, tendo em vista o próprio escopo da administração pública: concretizar o mandamento legal e, para tanto, deve se valer dos instrumentos que lhe são atribuídos, sendo que o principal deles é o exercício de poder regulamentar. É importante destacar que no ordenamento jurídico brasileiro o regulamento tem de respeitar as leis, não pode conter preceitos que contrariem disposições constantes de leis formais.

O ABNT (2006) conceitua regulamento e regulamento técnico. Um regulamento é concebido com um documento que formaliza regras que possuem um caráter obrigatório e que é estabelecido por uma autoridade. Com relação a regulamento técnico, esse guia diz que este normatiza requisitos técnicos, seja de forma direta, ou quando faz referência ou incorpora o conteúdo de uma norma, de uma especificação técnica ou de um código de prática, tornando-os de cumprimento obrigatório. Na esfera federal do Estado brasileiro, regulamento técnico é definido como:

Documento que enuncia as características de um produto ou os processos e métodos de produção a ele relacionados, incluídas as disposições administrativas aplicáveis, cujo cumprimento é obrigatório. Pode tratar parcial ou exclusivamente de terminologia, símbolos e requisitos de embalagem, marcação ou rotulagem aplicáveis a um produto, serviço, bens, pessoas, processo ou método de produção. (CONMETRO, 2007, p.5)

Por ser um documento que contém regras de caráter obrigatório, o regulamento técnico se caracteriza pela imposição efetuada pelo Poder Público à sociedade. Num regulamento, são estabelecidos requisitos técnicos, seja diretamente, seja pela referência ou incorporação do conteúdo de uma norma técnica, de uma especificação técnica ou de um código de prática (FERMAM, 2005). É importante salientar que as normas técnicas são entendidas como de caráter voluntário, entretanto sua referência ou transcrição em regulamentos por autoridades públicas as conferem um caráter compulsório, sendo a partir desse ato consideradas normas mandatórias. Norma mandatória é definida por $\operatorname{ABNT}(2006$, p.12) como "norma cuja aplicação é obrigatória em virtude de uma lei geral, ou de uma referência exclusiva em um regulamento".

Também é relevante mencionar que existem países e blocos regionais que adotam modelos de regimes regulatórios que valorizam a adoção das normas técnicas, até mesmo preservando o seu caráter voluntário, como os Estados Unidos e a União Européia. O Conmetro (2007, p. 4) considera ser imprescindível para a política brasileira de desenvolvimento industrial e de comércio exterior, que tanto os regulamentos aplicáveis a produtos, quanto os aplicados a bens, serviços, processos e pessoas, estejam alinhados com a prática internacional, facilitando o reconhecimento e aceitação destes por outros mercados. Essa recomendação pretende incentivar a normalização com a finalidade de utilização de normas técnicas na regulamentação, tema que será discutido mais adiante. As normas técnicas normalmente são utilizadas como requisitos para programas de avaliação da conformidade, regulamentados por autoridades regulamentadoras e executados por organismos de avaliação de conformidade acreditados. Na seção seguinte serão 
apresentadas algumas definições básicas relacionadas aos temas avaliação da conformidade e acreditação.

\section{Avaliação da Conformidade e acreditação}

Para ABNT (2005, p.1) avaliação da conformidade é a demonstração de que os requisitos especificados relativos a produto, processo, sistema, pessoa ou organismo são atendidos. Sendo que para essa norma, requisitos especificados correspondem à necessidade ou expectativa que é expressa em normas, regulamentos ou especificações técnicas e produto é o resultado de um processo, incluindo nesse conceito serviço, software ou hardware. A ABNT $(2005$, p.2) define que organismos de avaliação da conformidade como sendo um organismo que executa os serviços de avaliação da conformidade. Esse organismo é reconhecido formalmente por uma autoridade, geralmente do governo, que efetua uma atestação exprimindo uma demonstração formal da competência de um organismo de avaliação da conformidade para realizar tarefas específicas inerentes à avaliação da conformidade.

De acordo com o Inmetro (2007, p.39), acreditação é o reconhecimento formal, concedido por um organismo autorizado pelo Estado, de que a entidade foi avaliada, segundo guias e normas nacionais e internacionais e têm competência técnica e gerencial para realizar tarefas específicas de avaliação da conformidade. Nesse sentido, o órgão acreditador reconhece a competência técnica e gerencial de Organismos de Avaliação da Conformidade que por sua vez reconhecem a conformidade de um sistema de gestão, produto, processo, serviço ou pessoal.

Para Inmetro (2007, p.20), os principais mecanismos de avaliação da conformidade são: certificação, declaração da conformidade do fornecedor, inspeção, etiquetagem e ensaio. Estes mecanismos, no Brasil, são utilizados para a avaliação da conformidade com a participação de entidades particulares que têm reconhecidas, pelo Inmetro, a sua capacidade técnica para atuar nessas áreas. Por fim, antes de dar início ao capítulo que discorrerá sobre a possibilidade de utilização de normas técnicas em regulamentos técnicos, é importante apresentar o conceito de designação. Segundo ABNT (2005, p.6) a designação é a autorização emitida por entidade governamental para que um organismo de avaliação da conformidade possa realizar atividades específicas de avaliação da conformidade.

\section{Utilização de Normas Técnicas em Regulamentos}

Regulamentos técnicos podem estabelecer diretamente as características técnicas para produtos, métodos de ensaio e outros requisitos técnicos necessários à aplicação do regulamento ou então podem recorrer às normas técnicas para esse fim. Nesse sentido, compete, quando da regulamentação, à autoridade regulamentadora decidir se convém utilizar ou não normas técnicas (CONMETRO 2007, p.21). Para Conmetro (2007, p.21), ao se considerar a utilização de normas 
técnicas como base para a regulamentação, é importante que seja feita uma análise crítica do conteúdo da norma a fim de assegurar que ela contenha soluções apropriadas para atender às finalidades do regulamento técnico. Dependendo do problema, ou das circunstâncias relacionadas ao problema que se pretende resolver com a regulamentação, pode ser que, por diversas razões, os requisitos estabelecidos nas normas técnicas não sejam os mais adequados. Neste caso, pode ser necessário que a entidade regulamentadora opte por desenvolver os requisitos técnicos ou elabore um documento de adequação à norma técnica existente.

Esta hipótese pode se concretizar em determinados casos devido ao fato de que as autoridades regulamentadoras não possuem controle sobre o processo de normalização, fazendo com que os requisitos estabelecidos nas normas técnicas possam não ser apropriados para o regulamento técnico. Essa peculiaridade da normalização reforça a importância da autoridade regulamentadora se envolva ativamente no processo de elaboração e atualização das normas técnicas relacionadas aos temas atinentes à sua competência regulamentar. A participação das autoridades regulamentadoras no processo de normalização é recomendável toda vez que as normas técnicas forem ou puderem ser utilizadas como uma das formas de fornecer a base técnica para o atendimento à regulamentação técnica. De qualquer forma, considerando o fato da autoridade regulamentadora não possuir total controle sobre a normalização devido às suas características, a autoridade pode sempre deixar claro que, caso a norma técnica não atenda às suas necessidades, não a utilizará na regulamentação técnica.

O Brasil possui diversas autoridades regulamentadoras, as quais possuem culturas e tradições de regulamentação técnica próprias, cuja competência para elaborá-la é estabelecida em legislação específica. Essa situação propicia a coexistência de múltiplas abordagens e formas de estabelecer a regulamentação técnica brasileira, apontando a necessidade de adoção de orientações e recomendações para o alinhamento e sistematização do processo relativo ao seu desenvolvimento, adoção e implementação, consolidando a experiência desses órgãos e incorporando a essa atividade os desenvolvimentos recentes, ocorridos nos cenários nacional e internacional.

Foi considerando esse contexto que, conforme BRASIL (2007, p.4), o Conselho Nacional de Metrologia, Normalização e Qualidade Industrial - Conmetro decidiu publicar o Guia de Boas Práticas da Regulamentação Técnica, elaborado pelo Comitê Brasileiro de Regulamentação CBR, órgão assessor do citado Conselho, constituído por diversas autoridades regulamentadoras federais e outros órgãos do Estado, além da ABNT.

As boas práticas de regulamentação recomendam que, ao serem utilizadas normas técnicas como base para os regulamentos técnicos, convém que a autoridade regulamentadora o faça da forma mais simples possível para evitar confusões e defasagem tecnológica, já que as normas técnicas estão sujeitas a revisões periódicas. Para Conmetro (2007, p.4), a "adoção de boas práticas de regulamentação proporciona benefícios para a sua implementação, para a eficácia e eficiência da atuação do Estado no cumprimento dos seus objetivos legítimos, além de 
promover a cidadania, o progresso econômico e a minimização dos impactos ambientais, sociais e econômicos da regulamentação técnica".

Para finalizar as considerações acerca dos temas objeto do presente capítulo, é necessário frisar que o Guia de Boas Práticas da Regulamentação Técnica fornece orientações e recomendações para a elaboração, adoção e implementação de regulamentos técnicos, com o propósito de contribuir para a melhoria e aperfeiçoamento das práticas regulamentadoras brasileiras. Destina-se às autoridades brasileiras responsáveis pela elaboração, adoção e implementação de regulamentos técnicos, aplicáveis a produtos, serviços, bens, processos ou pessoas. (CONMETRO, 2007, p.4)

\section{Competências Legais dos entes Responsáveis por Implementar a Normalização e a Normalização no Brasil}

Como já mencionado, o Brasil, por ser uma República Federativa, possui diversas autoridades regulamentadoras nos níveis federal, estadual e municipal com competências legais para regulamentação estabelecidas na constituição federal e na legislação nacional. Especificamente com relação à normalização e avaliação da conformidade, Brasil (1973) institui o Sistema Nacional de Metrologia, Normalização e Qualidade Industrial - Sinmetro com a finalidade de formular e executar a política nacional de metrologia, normalização industrial e certificação de qualidade de produtos industriais. Essa Lei estabelece as entidades públicas e privadas que compõem o sistema. Também cria o Conselho Nacional de Metrologia, Normalização e Qualidade Industrial - Conmetro como um colegiado interministerial que exerce a função de órgão normativo do Sinmetro e que tem o Inmetro como sua Secretaria Executiva. Integram o Conmetro os ministros do Desenvolvimento, Indústria e Comércio Exterior; da Ciência e Tecnologia; da Saúde; do Trabalho e Emprego; do Meio Ambiente; das Relações Exteriores; da Justiça; da Agricultura, Pecuária e do Abastecimento; da Defesa; o Presidente do Inmetro e os Presidentes da ABNT, da Confederação Nacional da Indústria - CNI e do Instituto de Defesa do Consumidor - IDEC.

Segundo Inmetro (2007, p.49), o Inmetro é o único organismo acreditador do Brasil reconhecido no âmbito do Sinmetro. Desta forma, o Inmetro pode acreditar Organismos de Certificação para efetuar a certificação de sistemas de gestão, inclusive de sistemas de gestão da segurança e saúde no trabalho.

De acordo com Brasil (1999), o Inmetro também possui competência para exercer poder de polícia administrativa, expedindo regulamentos técnicos nas áreas de avaliação da conformidade de produtos, insumos e serviços, desde que não constituam objeto da competência de outros órgãos ou entidades da administração pública federal, abrangendo dentre outros aspectos relativos a segurança e para proteção da vida e da saúde humana. O Inmetro pode também executar, coordenar e supervisionar as atividades de metrologia legal e de avaliação da conformidade compulsória por ele regulamentadas ou exercidas por competência que lhe seja 
delegada. Contudo, é relevante mencionar que o MTE é a autoridade regulamentadora legalmente habilitada para emitir regulamentos técnicos referentes ao tema segurança e saúde no trabalho, por meio das Normas Regulamentadoras, com competência instituída pelo artigo 200 do DecretoLei $n^{\circ} 5.452$, de $1^{\circ}$ de maio de 1943.

\section{Sistemas de Gestão da Segurança e Saúde no Trabalho o Mundo, a Situação do Brasil e o Modelo Proposto pela ABNT NBR 18801}

Organização Internacional do Trabalho (OIT) coloca que muitos países formularam estratégias nacionais de segurança e saúde no trabalho que integram, igualmente, a abordagem dos sistemas de gestão, SGSST. A OIT publicou em 2001 o documento Sistemas de gestão da segurança e saúde no trabalho: Diretrizes práticas da OIT, com abordagem tripartida que se tornou num modelo utilizado para o desenvolvimento de normas nacionais nessa área.

Devido a impasse estabelecido entre a ISO e a OIT, com relação a competências para elaboração, não foi até hoje elaborada norma internacional com requisitos de sistemas de gestão de segurança e saúde no trabalho. A própria OIT relata que o Conselho de Administração da OIT reafirmou, em 2007, a competência da OIT em matérias relacionadas a segurança e saúde no trabalho e, por esse motivo, solicitou à ISO que se abstivesse de desenvolver uma norma internacional de SGSST. Já Cerqueira (2010, p.129) afirma que a ISO decidiu não elaborar normas para SGSST, por considerar que o tema não era de interesse internacional.

Devido à lacuna existente com relação à normalização em SGSST, tanto de normalização internacional e nacional, como de regulamentação técnica, no Brasil, as organizações privadas preocupadas com o seu resultado em segurança e saúde no trabalho normalmente adotam a norma Occupational Health and Safety Assessment Series - OHSAS 18001 que teve a elaboração conduzida pela Instituição Britânica de Normalização (British Standarts Institution - conhecida pela sigla BSI). A referida norma, cuja primeira versão foi publicada em1999 e revisada em 2007, é uma norma adotada por empresas e objeto de certificação na maioria dos países do mundo. $A$ OHSAS 18001 não é considerada uma norma técnica internacional, sendo classificada nos países na categoria de normas estrangeiras, pois a sua elaboração não foi conduzida pela ISO.

Nos últimos anos, a aplicação de SGSST, foi alvo da atenção de empresas, governos e organizações internacionais enquanto estratégia para harmonizar as necessidades de empresas e de segurança e saúde do trabalho e assegurar que trabalhadores possam participar mais efetivamente na implementação de medidas preventivas. Durante a última década, a abordagem sistêmica da gestão de segurança e saúde no trabalho tornou-se popular e foi introduzida, na grande maioria dos países, tanto em nações industrializadas como em países em desenvolvimento, por meio de disposições regulamentares ou de mecanismos voluntários. Em países como Indonésia, Noruega e Singapura os SGSST foram introduzidos por meio de regulamentação, tornando sua adoção obrigatória pelo menos para empresas específicas. Já 
países como a Austrália, Nova Zelândia, China, Taiwan e Tailândia houve a introdução por meio de normas nacionais voluntárias com suporte de mecanismos de certificação. Enquanto que, no estudo na OIT, Hong-Kong, Japão e Coréia implantaram sistemas voluntários por meio da promoção de linhas orientadoras nacionais de SGSST elaboradas por uma entidade nacional de normalização e países como Índia e Malásia adotaram um SGSST de adoção voluntária baseado nas Diretrizes da OIT. Vários países como Estados Unidos da América, Portugal, África do Sul, Nova Zelândia, dentre outros, já possuem normas técnicas nacionais referentes a sistema de gestão. No Brasil, a ABNT propiciou a discussão do texto e, em dezembro de 2010, publicou a ABNT NBR 18801 - Sistema de Gestão de Segurança e Saúde no Trabalho, com vigência prevista para dezembro de 2011.

Em outubro de 2011, o MTE (2011), constituiu o Grupo de Estudos Tripartite com o objetivo de estudar e contribuir com a proposta de texto técnico básico para criação de Norma Regulamentadora sobre a Gestão da Segurança e Saúde no Trabalho. O grupo é composto por representantes do governo, empregadores e empregadores e trabalhadores indicados formalmente pelas entidades públicas e privadas que compõem a Comissão Tripartite Paritária Permanente - CTPP, sendo o governo representado pelo Departamento de Segurança e Saúde no Trabalho do MTE, pela Fundação Jorge Duprat Figueiredo de Segurança e Medicina do Trabalho - Fundacentro, pelo Departamento de Políticas de Saúde e Segurança Ocupacional do Ministério da Previdência Social, e a coordenação dos trabalhos é exercida pelo membro indicado pela Secretária de Inspeção do Trabalho do MTE.

Em novembro de 2011, mediante solicitação do MTE, a ABNT prorrogou o início da vigência da ABNT NBR 18801 para dezembro de 2014, com justificativa da expedição do Decreto $n^{\circ} 7.602$, de novembro de 2011, e de discussões no MTE da Norma Regulamentadora $n^{\circ} 35$ que se refere ao mesmo tema objeto da norma ABNT. Adicionalmente, em abril de 2012, os Ministérios da Saúde, Previdência Social e Trabalho e Emprego lançaram o Plano Nacional de Segurança e Saúde no Trabalho - PLANSAT, o qual também prevê o desenvolvimento pelo MTE de uma Norma Regulamentadora - NR relativa à SGSST, ação 6.1.3 do PLANSAT, e a articulação com a ABNT para a adequação da NBR 18801 à NR de SGSST do MTE, ação 6.1.1 do referido plano. Como não é objetivo do presente trabalho o aprofundamento da discussão e interpretação da ABNT NBR 18801:2010, a seguir apresentaremos uma visão básica do Modelo Brasileiro de SGSST proposto nessa norma.

O modelo, conforme Figura 2 é alicerçado no modelo de atuação tripartite preconizado pela OIT, com responsabilidades para o governo, empregador e trabalhador. Nesse sentido, a norma preconiza que cabe ao trabalhador participar em saúde e segurança do trabalho e cumprir instruções de saúde e segurança do trabalho, ao empregador implantar cultura da preventiva, garantir ambiente saudável e seguro e envolver os trabalhadores em saúde e segurança do trabalho, e compete ao governo fomentar políticas e programas de saúde e segurança do trabalho. Esse modelo está baseado num sistema aberto e está calçado por seis princípios: 
participação do trabalhador, compromisso da Alta Administração, cultura de prevenção, capacitação específica em saúde e segurança do trabalho, envolvimento das partes interessadas e incidentes fora do trabalho; com foco na prevenção e controle de riscos e na melhoria contínua do desempenho em saúde e segurança do trabalho.

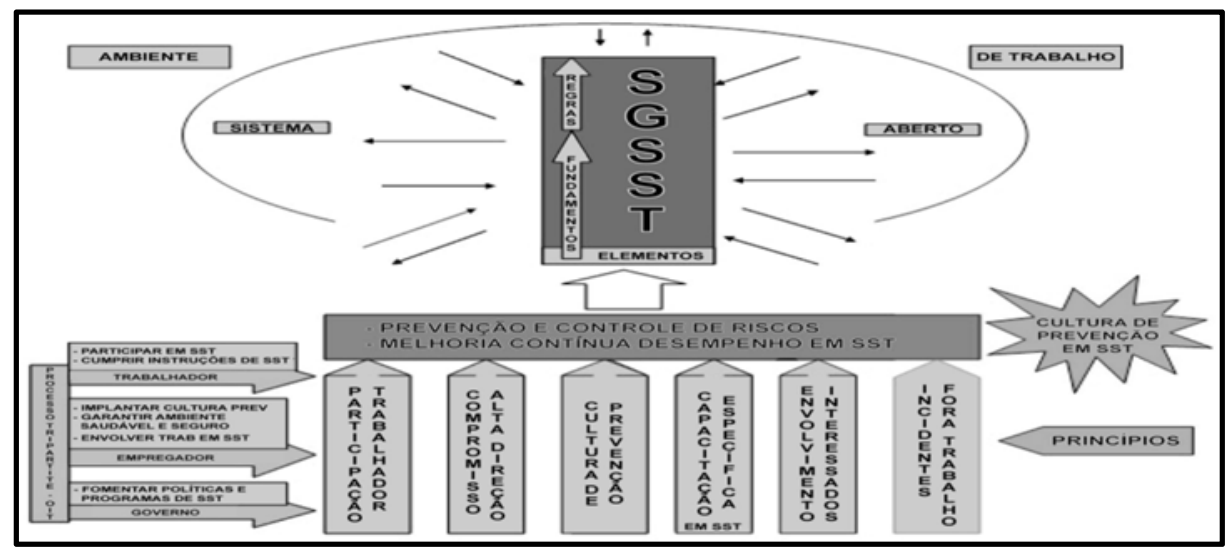

Figura 2: Modelo Brasileiro de Sistema de Gestão de Segurança e Saúde no Trabalho.

Fonte: ABNT (2010).

A norma apresenta um grupo de elementos gerais para SGSST que discorrem sobre a participação dos trabalhadores, controle social, política de saúde e segurança do trabalho e requisitos gerais. Apesar de ter sido baseada na OHSAS 18001, a qual se sustenta no ciclo de desenvolvimento com foco na melhoria contínua PDCA (do inglês Plan, Do, Check e Act), também conhecido como ciclo de Shewhart ou ciclo de Deming, a ABNT (2010), mesmo apresentando na figura 3 o processo de melhoria contínua em espiral, utiliza a sigla e palavras inglesas do ciclo PDCA, os quais são traduzidos para a realidade brasileira no modelo de sistema de gestão com os elementos Planejar, Executar, Verificar e Agir, dispostos nos itens 3.5, 3.6, 3.7 e 3.8 da ABNT (2010).

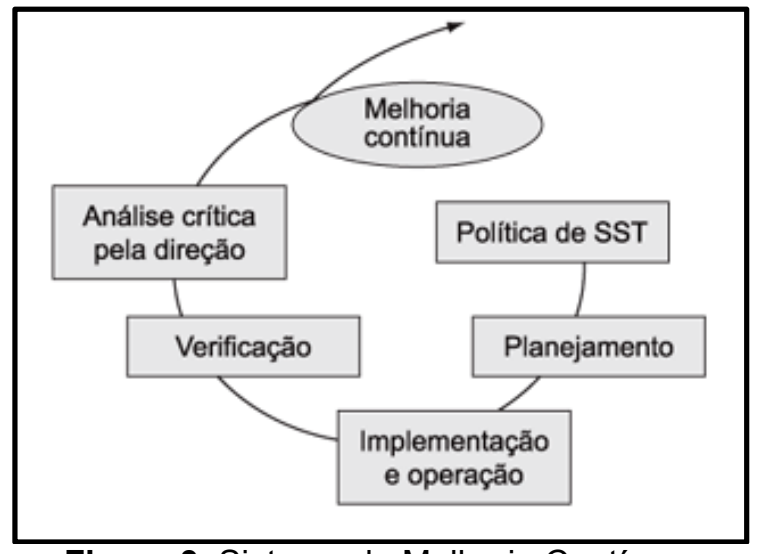

Figura 3: Sistema de Melhoria Contínua.

Fonte: ABNT (2010).

A norma apresenta um grupo de elementos gerais de sistema de gestão que discorrem sobre a participação dos trabalhadores, controle social, política de saúde e segurança do trabalho 
e requisitos gerais, e em seguida o modelo de melhoria contínua com elementos intitulados Planejar, Executar, Verificar e Agir, detalhados na figura 4.

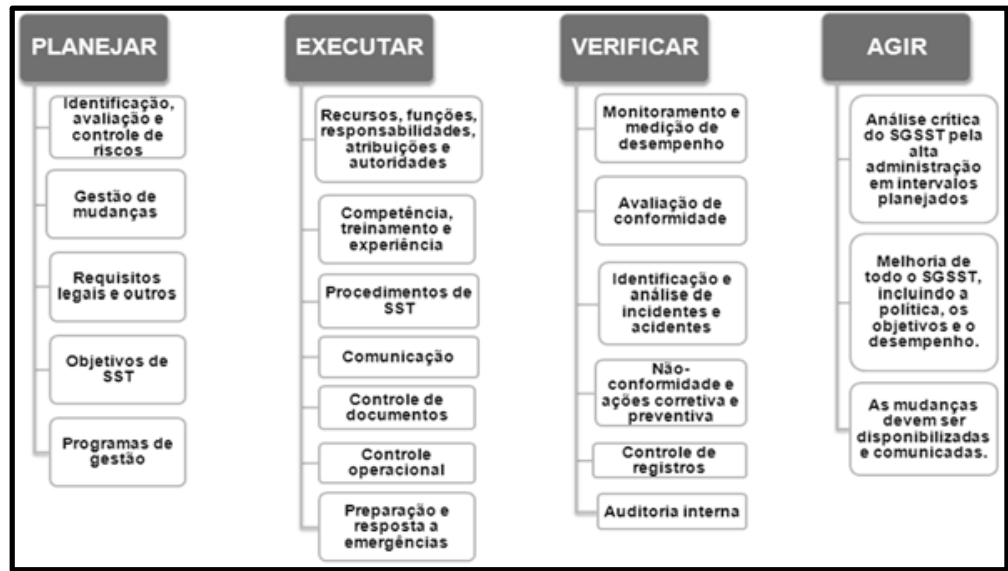

Figura 4: Elementos do Sistema de Gestão de Segurança e Saúde no Trabalho.

Como o aprofundamento da discussão quanto ao teor do modelo proposto na ABNT NBR 18801 (2010) não é o propósito do presente artigo, será apresentado a seguir as considerações sobre a normalização e a regulamentação de SGSST discutidas no Brasil.

\section{RESULTADOS}

A seguir serão apresentadas posições divergentes de discussões que vem sendo travadas no Brasil relacionadas à normalização e regulamentação de SGSST e, em seguida, serão incorporadas algumas considerações atinentes ao tema. Um dos integrantes do grupo que discutiu e conduziu à publicação da ABNT NBR 18801, ao conceder entrevista à Revista Proteção relatou:

Agora vemos que a CTPP (Comissão Tripartite) está discutindo uma NR de gestão, o que acho um absurdo. Uma lei não pode definir como uma empresa deve gerir os seus negócios. Quando definimos o sistema de gestão da 18801 pensamos em uma gestão que seja integrada ao negócio da empresa. Como é possível criar uma lei que vai definir como gerir isso? Gestão é algo estratégico para uma empresa, não se define por meio de lei (COLETTO, 2011, p.8).

As argumentações de Coletto (2011) são em defesa da normalização e contrárias à regulamentação, argumentando ser absurda a proposta do MTE de desenvolver uma Norma Regulamentadora de gestão na medida em que esse dispositivo regulamentador estaria interferindo na gestão da empresa, a qual para ele seria algo estratégico que, por esse motivo, não deveria ser objeto de regulamentação.

Em contraposição, o Engenheiro de Segurança do Trabalho, Rinaldo Marinho Costa Lima, Diretor do Departamento de Segurança e Saúde do Trabalhador - DSST da Secretaria de Inspeção no Trabalho do MTE, ao ser questionado se a ABNT NBR 18801 teria servido de base para a Norma Regulamentadora de sistema de gestão de SST que vinha sendo discutida no MTE responde que não, Lima (2011, p.20), e menciona o fato do MTE ter sido contrário a essa norma, 
por meio de consenso entre as três bancadas da composição tripartite de discussão (empregadores, trabalhadores e governo) o qual culminou com o envio de documento à presidência da ABNT para informar que esse tema entraria na pauta de regulamentação do MTE, mas reclama que a ABNT ignorou tal documento prosseguindo nas discussões que culminaram com a publicação da ABNT NBR 18801, em dezembro de 2010.

Em seguida, Lima (2011) relata que não existe semelhança entre as duas normas, fundamentando essa afirmação por meio do aspecto distintivo entre norma técnica e regulamento técnico. Lima (2011) explica a obrigatoriedade de cumprimento, imposta pela norma regulamentadora do MTE, ante ao aspecto voluntário presente na ABNT NBR 18801, o que, segundo o autor, pode ocasionar conflito na aplicabilidade para os empregadores, já que a fiscalização do MTE sempre exigirá o cumprimento da norma regulamentadora independentemente da adoção pelas empresas de outra(s) norma(s).

Gueiros Júnior e Lopes (2000) apresentaram uma proposta de desregulamentação e flexibilização da legislação do trabalho com a instituição do que os autores denominaram Certificação Pública para a Qualidade nos Ambientes do Trabalho. Nesse trabalho não ficou claro se a certificação seria 'emitida por uma Auditoria Fiscal do Trabalho delegada pelo Estado' Gueiros Júnior e Lopes (2000, p.13), pois os autores propuseram na página 14 do mesmo trabalho a instituição de “(...) uma cultura de Auditoria, proativa, instrumentalizada pela Certificação e Acreditação Oficial, nos moldes do INMETRO, utilizando-se a mesma linguagem da globalização. A Inspeção do Trabalho assume definitivamente a função de Auditoria Fiscal do Trabalho, e, ao invés de uma fiscalização".

Aparentemente, embora os autores tenham proposto uma atuação nos mesmos moldes do Inmetro, eles não teriam aplicado exatamente os mesmos conceitos e instrumentos relativos à certificação e acreditação ora vigentes e já mencionados no presente estudo. Ao utilizar os conceitos e instrumentos atuais relacionados à acreditação e certificação, caberia ao Inmetro, como órgão oficial de acreditação do Brasil, reconhecer a competência técnica e gerencial de Organismos Certificação de Sistemas de Gestão de Segurança e Saúde no Trabalho, que seriam entidades que conduziriam e efetuariam a avaliação da conformidade e concederiam a certificação com base em norma de sistema de gestão de saúde e segurança no trabalho ou nos requisitos técnicos constantes da Norma Regulamentadora do MTE, podendo inclusive ser a Norma Regulamentadora $n^{\circ} 2$ que, conforme proposta de Gueiros Júnior e Lopes (2000, p.16), seria alterada para incorporar as mudanças propostas e incluir requisitos relativos à SGSST que deveriam ser cumpridos pelas empresas.

Poderia também ser utilizada pelo MTE a figura da designação, sendo designado formalmente um ou mais Organismos Certificação de Sistemas de Gestão de Segurança e Saúde no Trabalho previamente acreditado pelo Inmetro para que somente entidade(s) acreditada(s) $\operatorname{possa}(m)$ efetuar a avaliação da conformidade e conceder certificações de SGSST, com a possibilidade de o MTE estabelecer os critérios que se fizerem necessários e fiscalizar a atuação 
de OCT designado da forma mais adequada. A proposta de Gueiros Júnior e Lopes (2000, p.16) prevê certificação variável com escala de gradação mínima, satisfatória, adequada ou plena, de acordo com o grau de maturidade dos SGSST das empresas. A proposta dos referidos autores também insere a possibilidade da participação do Ministério da Previdência Social no processo.

Seguindo essa linha de raciocínio, constata-se que é essencial uma atuação conjunta e articulada entre o MTE e o Ministério da Previdência Social - MPS. Essa afirmativa é reforçada pela recente atuação do MPS com relação a saúde e segurança no trabalho, com a criação do Departamento de Políticas de Saúde e Segurança Ocupacional, por meio do Decreto $n^{\circ} 6.194$, de 22 de agosto de 2007, e a regulamentação do Nexo Técnico Epidemiológico Previdenciário NTEP e do Fator Acidentário de Prevenção - FAP e o monitoramento dos benefícios por incapacidade concedidos pela Previdência Social. Já em 2003, Brasil (2003) dispunha que a alíquota de contribuição de um, dois ou três por cento, destinada ao financiamento do benefício de aposentadoria especial ou daqueles concedidos em razão do grau de incidência de incapacidade laborativa decorrente dos riscos ambientais do trabalho, poderia ser reduzida, em até cinquenta por cento, ou aumentada, em até cem por cento, conforme dispuser o regulamento, em razão do desempenho da empresa em relação à respectiva atividade econômica, apurado em conformidade com os resultados obtidos a partir dos índices de frequência, gravidade e custo, calculados segundo metodologia aprovada pelo Conselho Nacional de Previdência Social.

A metodologia, conforme CNPS (2010) trata o FAP como instrumento da política pública de prevenção de riscos ambientais do trabalho buscando mensurar a efetividade dos controles de riscos ambientais do trabalho nas empresas. O objetivo do FAP, de acordo com CNPS (2010), é incentivar a melhoria das condições de trabalho e da saúde do trabalhador estimulando as empresas a implementarem políticas mais efetivas de saúde e segurança no trabalho para reduzir a acidentalidade. Esse aspecto é reforçado por Brasil (1999) ao estabelecer que:

A fim de estimular investimentos destinados a diminuir os riscos ambientais no trabalho, o Ministério da Previdência e Assistência Social poderá alterar o enquadramento de empresa que demonstre a melhoria das condições do trabalho, com redução dos agravos à saúde do trabalhador, obtida através de investimentos em prevenção e em sistemas gerenciais de risco (BRASIL, 1999, p.2).

Constata-se, portanto, que a certificação de sistemas de gestão de saúde e segurança no trabalho poderia ser utilizada efetivamente como um dos mecanismos de avaliação dos resultados da empresa para fins de aplicação do FAP, podendo o MPS beneficiar empresas que demonstrem investimentos em prevenção e em sistemas gerenciais de riscos do trabalho que tenha como meta a redução da acidentalidade, nesse conceito se inserindo os SGSST.

Reforçando essa proposta de valorização das empresas com bons resultados, os autores Gueiros Júnior e Lopes (2000, p.16), propõem a proibição da participação em licitação e celebração de contratos com entes públicos para as empresas que não possuam certificação. Também prevê a utilização de sistema de pontuação positiva para empresas que tenham melhorias sociais e negativas para empresas recorrentes na justiça trabalhista ou que explorem o trabalho infantil. Na proposta de Gueiros Júnior e Lopes (2000, p.16), caso a empresa recebesse 
certificação positiva poderia ser retirada da lista de prioridades da inspeção do trabalho e se as empresas que perdessem certificação ficaram sujeitas às fiscalizações convencionais. Os mesmos autores sugerem no modelo proposto que a vigilância do processo de certificação seja realizada pelos trabalhadores e sindicatos.

Para os referenciados autores, a proposta poderia ser instrumentalizada por meio da alteração da NR $n^{\circ} 2$ do MTE, com adoção da certificação em detrimento do auto de infração, não havendo mais multa para as empresas aderentes e com a adoção de um sistema dependente de controle social, com ampla divulgação dos resultados das empresas, inclusive com a publicação das certificações e respectiva pontuação de cada empresa em um anuário.

\section{CONCLUSÕES}

O presente estudo baseou-se nos conceitos e possibilidades de utilização da normalização, regulamentação, acreditação e avaliação da conformidade, no âmbito do Sinmetro, na discussão do tema sistema de gestão da segurança e saúde no trabalho, tema em debate concomitante por uma autoridade regulamentadora e uma entidade de normalização oficial do Brasil.

Retomando a linha de pensamento do Diretor do DSST do MTE, com relação à distinção entre normas técnicas e regulamentos técnicos, evidencia-se que essa deve ser observada de maneira mais ampla, pois empresas podem adotar ou não uma norma técnica ou cumprir regulamento, sendo o caráter compulsório ou voluntário dependente das consequências pelo cumprimento ou eventual inobservância. Esse raciocínio é justificável se for considerado, por exemplo, que, mesmo normas técnicas poderão ter seu cumprimento considerado essencial a não ocorrência ou minimização de perdas ou prejuízos ou para a obtenção de vantagens e benefícios advindos do mercado ou do atendimento de necessidades da sociedade, relacionados à imagem institucional e à competitividade empresarial.

Por outro lado, regulamentos sem os mecanismos de fiscalização, sanção e acompanhamento adequados, por exemplo, podem favorecer seu descumprimento já que empresas farão avaliação custo-benefício e, em determinados casos, pode constatar ser mais vantajoso descumprir um regulamento (custos para o cumprimento dos requisitos maiores que os decorrentes da sua inobservância devido a baixas penalidades estabelecidas ou a pouca probabilidade de punição). Conforme ABNT (2006, p.12), existe a possibilidade de utilização do conceito de norma mandatória, ou seja, uma "norma cuja aplicação é obrigatória em virtude de uma lei geral, ou de uma referência exclusiva em um regulamento", lembrando que referência exclusiva é aquela que única maneira de atender aos requisitos de um regulamento técnico é estar em conformidade com a norma referenciada no regulamento.

A autoridade regulamentadora poderá tornar uma norma técnica, como a ABNT NBR 18801, mandatória e efetuar a respectiva e adequada fiscalização. Adicionalmente, como já 
relatado e conceituado, a autoridade regulamentadora, no caso o MTE, poderia utilizar-se da figura da designação de Organismos Acreditados de Certificação de SGSST. Esses organismos seriam responsáveis pela avaliação da conformidade dos SGSST e consequente concessão da certificação específica. As regras de realização das atividades e a forma de atuação dos organismos designados seriam definidas e fiscalizadas pelo MTE. Para a adoção de uma ou mais normas técnicas, ou parte delas, em um regulamento, poderá a autoridade regulamentadora celebrar acordo com a ABNT para a viabilização de espaço para a discussão da norma técnica até a sua publicação, conforme as suas necessidades, e para que sejam disponibilizadas cópias da norma para todas as organizações interessadas na certificação com base no SGSST publicado.

Com base nos estudos ora apresentados, constata-se que o sistema legal brasileiro permite a adoção de alternativas à regulamentação tradicionalmente implementada pelas autoridades de regulamentação, com a possibilidade de estabelecimento de arranjos regulatórios de regulamentação técnica que permitem a utilização das normas técnicas de diversas formas, conforme a conveniência e necessidade da autoridade regulamentadora. Contudo, do estudo, conclui-se que cabe à autoridade regulamentadora avaliar a situação e decidir pela adoção ou não de norma técnica e, caso opte pela não adoção, seria de bom tom, que fossem observadas as recomendações concernentes a boas práticas de regulamentação, conforme CONMETRO (2007).

Por fim, é importante destacar que o Conmetro poderia atuar como instância de aproximação das discussões tratadas no presente artigo e que estudos adicionais relacionados ao tema podem e devem ser desenvolvidos com o objetivo de tornar viável um processo de discussão que permita sinergia e utilização das potencialidades da autoridade de regulamentação e do organismo de normalização, com possibilidade de atuação complementar com participação do Inmetro, CBR, CBN e CBAC.

\section{REFERÊNCIAS}

ABNT. Sistema de gestão da segurança e saúde no trabalho. Rio de Janeiro: ABNT, 2010.

ABNT. Normalização e atividades relacionadas: vocabulário geral. Rio de Janeiro: ABNT, 2006.

ABNT. Avaliação da conformidade: vocabulário e princípios gerais. Rio de Janeiro: ABNT, 2005.

BRASIL. Lei ${ }^{\circ}$ 5.966/1973 de 12 de Dezembro de 1973. Institui o Sistema Nacional de Metrologia, Normalização e Qualidade Industrial e dá outras providências. Brasília, 12 Dez 1973.

BRASIL. Decreto n 3.048/1999 de 7 de Maio de 1999. Aprova o Regulamento da Previdência Social, e dá outras providências. Brasília, 7 Mai 1999.

BRASIL. Lei $n^{\circ}$ 9.933/1999 de 21 de Dezembro de 1999. Dispõe sobre as competências do Conmetro e do Inmetro, institui a Taxa de Serviços Metrológicos, e dá outras providências. Brasília, 21 Dez 1999.

BRASIL. Lei $\mathbf{n}^{\circ} \mathbf{1 0 . 6 6 6 / 2 0 0 3}$ de 9 de Maio 2003. Dispõe sobre a concessão da aposentadoria especial ao cooperado de cooperativa de trabalho ou de produção e dá outras providências. Brasília, 9 Mai 2003.

CERQUEIRA, J.. Sistemas de Gestão Integrados: ISO 9001, ISO 14001, OHSAS 18001, SA 8000 e NBR 16001: conceitos e aplicações. Rio de Janeiro: Qualitymark, 2010. 
COLETTO, J.. Ação positiva: profissional precisa falar a linguagem do empresário e criar indicadores proativos. Revista Proteção, n.230, p.8-14, 2011.

CNPS. Conselho Nacional de Previdência Social. Resolução MPS/CNPS n 1316/2010 de 15 de Junho de 2010. Brasília, 15 Jun 2010.

CONMETRO. Conselho Nacional de Metrologia, Normalização e Qualidade Industrial. Resolução $\mathbf{n}^{\circ} \mathbf{5}$, de 18 de dezembro de 2007. Guia de Boas Práticas de Regulamentação. Brasília, 2007.

FERMAM, R. K. S.. As Negociações do Mercosul com a União Européia no âmbito das Barreiras Técnicas ao Comércio. Dissertação (Mestrado em Ciências) - Universidade Federal do Rio de Janeiro, Rio de Janeiro, 2005.

GUEIROS JÚNIOR, S.; LOPES, A. S.. Globalização, flexibilização e desregulamentação. Modelos emergentes para a inspeção do trabalho. Jus Navigandi: Teresina, v.6, n.51, 2001.

INMETRO. Avaliação da Conformidade: Diretoria da Qualidade. 5 ed. Rio de Janeiro: Inmetro, 2007.

LIMA, R. M. C.. CIPA entrevista: DSST sob nova direção. Revista CIPA, n.378, p.18-32, 2011.

MITRULIS, L. M.. A normalização e a ABNT: Contribuição à Análise de Especificações de Componentes de Rodovias e Melhoria da Qualidade de Viagens. Tese (Doutorado em Engenharia Civil) - Universidade de São Paulo, São Paulo, 2003.

MTE. Ministério do Trabalho e Emprego. Portaria MTE n $280 / 2011$ de 4 de Novembro de 2011. Constitui Grupo de Estudos Tripartite sobre a Gestão da Segurança e Saúde no Trabalho. Brasília, 4 Nov 2011

OLIVEIRA, C. L. C.. Normalização como suporte à regulamentação. Brasília: SENAI, 2010. 